\title{
Is the role of regional secure units changing?
}

\author{
Jeanetre Smith, Senior Registrar in Forensic Psychiatry, The Butler Clinic, Langdon \\ Hospital, Exeter Road, Dawlish, Devon EX1 0NR; Julian PARKER, formerly \\ Registrar, The Butler Clinic; and MARTIN Donovan, Consultant Forensic Psychiatrist \\ and Medical Director, The Butler Clinic
}

Regional secure units are a relatively new facility for the treatment of mentally disordered offenders and difficult to manage patients. Their role is still evolving. Previous studies have described details of referrals and admissions to such secure units (Higgins, 1981; Gudjonsson \& Mackeith, 1983; Offen \& Taylor, 1985; Faulk \& Taylor, 1986; Bullard \& Bond, 1988). To date, however, no studies have examined changes of practice in RSUs over time. The purpose of the present study is to examine changes in the admission characteristics of patients admitted to the Butler Clinic, regional secure unit for Devon and Cornwall since it opened in 1983 to the present time.

\section{The Butler Clinic}

The Butler Clinic opened in 1983. It is a 30-bedded regional secure unit, covering the catchment area of Devon and Cornwall (population one and a half million). It is a locked unit catering for male and female patients who may need to be managed for up to 18 months in a highly staffed facility. All patients are detained under the Mental Health Act. Admission criteria have not been rigidly defined and referrals to the Butler Clinic are assessed jointly by senior members of the medical and nursing staff. In general, the emphasis has been on adopting a flexible approach and assessing each patient's needs individually. Admissions during the early years were restricted by understaffing but the unit is now functioning at full capacity and by 1989 the annual admission rate had risen to 47 .

\section{The study}

The case notes of all patients admitted to the Butler Clinic between June 1983 and Deceber 1989 were examined. Details of background, psychiatric and offending history were extracted and recorded on the Devon and Cornwall Forensic Psychiatric Computerised Case Register. Patients admitted before 1986 $(n=46)$ were compared with a similar sized group $(n=53)$ of recent admissions. An intermediate group $(n=42)$ was not included in the study. Differences between the early and recent admissions on each item recorded were assessed for statistical significance using the $\chi^{2}$ test and the t-test.

\section{Findings}

Information was collected under the headings: location on referral, reason for referral, legal status on admission, diagnosis, index offence(s), previous convictions, institutional history and behavioural history. In this study, only variables where a significant change has been observed over time will be described. A comprehensive description of all admissions to the unit has previously been documented (Smith et al, 1991).

\section{Diagnoses}

These were assigned according to ICD-9 criteria. Although an increase in the proportion of patients suffering from schizophrenia and affective disorder was observed, this change did not reach statistical significance. In many patients, psychosis occurred in the setting of an antisocial personality disorder. However, the percentage of patients diagnosed as suffering from personality disorder alone dropped considerably from $52 \%$ to $25 \%(P<0.01)$ over the study period.

\section{Previous convictions}

The average number of previous convictions fell from 6.7 to $3.8(P<0.05)$. In particular, recent admissions had a less extensive history of acquisitive property offences $(P<0.001)$. There was also a trend towards fewer public order and sex offences.

\section{Institutional history}

The average number of previous admissions to psychiatric hospitals fell from 4.1 to $2.0(P<0.01)$. The proportion of patients with experience of penal institutions, special hospitals and other RSUs was, however, unchanged.

\section{Behavioural history}

A history of aggression towards care staff became less common, falling from $46 \%$ to $23 \%(P<0.05)$. 
Similarly, fewer of the recent admissions had a history of absconding, the proportion dropping from $54 \%$ to $25 \%(P<0.05)$.

\section{Comment}

Regional secure units were established to manage mentally disordered offenders and psychiatric patients posing management problems such as violence and absconding. This study suggests that the type of patients admitted to one RSU have changed. In particular, recent admissions are less likely to have a diagnosis of personality disorder alone. Also of note is their less extensive experience of psychiatric hospitals and history of aggression, absconding, and criminal convictions. Clearly the fall in number of personality diosordered patients admitted may account for these other changes.

Factors contributing to these changes may be associated with the changing function of the RSU. By common consent, RSUs fulfilled an unmet need. There may therefore have been a backlog of severely disturbed patients requiring a secure placement who were admitted as soon as the unit opened. If this was so, the referral rate would have been very high shortly after the unit opened and then should have gradually levelled off. This has not happened: referral rates have steadily increased providing little support for such a hypothesis. However, due to staff shortages, the unit opened its beds gradually and initially may only have been able to accept the most severely disturbed patients. As full details of all patients referred to the unit are not available, this possibility cannot be tested.

Admission criteria may perhaps have changed with experience. As previously indicated, these criteria have not been rigidly defined. Patient outcome has not been objectively measured, but the authors' impression has been that personality disordered patients make little progress in the unit. This may have led to an increasing reluctance to admit such patients.

The changing RSU patient population may be due to changes in the behaviour of the referring agencies. Their early experiences of the RSU, when many highly disturbed patients were accepted, could have led to the referral of less disturbed patients as well. Once again this hypothesis cannot be tested without comprehensive information on all referrals.
In 1981, the Royal College of Psychiatrists (Royal College of Psychiatrists, 1981) pointed out that due to variation in populations and hospital services, the regions' needs for secure facilities differed and it recommended that regional secure facilities should be integrated with general psychiatric services in the region. Not only will the role of the secure unit vary from one area to another, but as general services change, this may be reflected in changes in the RSU patient population. It is quite likely that the changes in the RSU patient population observed in this current study reflect changes in local psychiatric services. During the study period closure of long term in-patient facilities for the mentally ill has been as rapid in the South West as elsewhere. Indeed, some of the districts in the catchment area of the Butler Clinic (e.g. Torbay and Exeter) have led the country in this respect. As a result there has been a relative shortage of facilities and skills to manage difficult patients at a local level. Perhaps some of the recent admissions to the RSU who were less disturbed than their predecessors were referred because they could be inadequately provided for by local services. If this latter hypothesis is correct, the trend for less disturbed patients to be admitted to RSUs is likely to continue. The resource implications are substantial. Further research is needed to clarify these issues.

\section{References}

BULLARD, H. \& BOND, M. (1988) Secure units: why they are needed. Medicine, Science and the Law, 28, 312-318.

FAulk, M. \& TAYloR, J. C. (1986) Psychiatric interim secure unit: seven years experience. Medicine, Science and the Law, 26, 17-22.

Gudsonsson, G. H. \& McKeith, J. A. C. (1983) A regional interim secure unit at the Bethlem Royal Hospital - the first fourteen months. Medicine, Science and the Law, 23, 209-219.

HigGins, J. (1981) Four years experience of an interim secure unit. British Medical Journal, 282, 889-893.

OFFEN, L. \& TAYLOR, P. J. (1985) Violence and resources: factors determining admission to an interim secure unit. Medicine, Science and the Law, 25, 165-171.

Royal College of Psychiatrists (1981) Secure Facilities for Psychiatric Patients, a Comprehensive Policy. Unpublished Report.

Smith, J. E., PARker, J. \& Donovan, W. M. (1991) Female admissions to a regional secure unit. The Journal of Forensic Psychiatry (in press). 